\title{
Amplification and deformation of tidal wave in the Upper Scheldt Estuary
}

\author{
Zheng Bing Wang ${ }^{1,2}(\mathbb{D}) \cdot$ Wouter Vandenbruwaene $^{3} \cdot$ Marcel Taal $^{1} \cdot$ Han Winterwerp ${ }^{1,2}$
}

Received: 7 November 2018 / Accepted: 6 June 2019 / Published online: 22 June 2019

(C) The Author(s) 2019

\begin{abstract}
The records of HW and LW in the most upper part of the Scheldt Estuary since 1971 have been analysed together with the daily river discharge. The tidal range, the hydraulic head and the ratio between the rising tide period to falling tide period have been determined for investigating the tidal amplification, the water surface slope along the river and the tidal asymmetry. The purpose of the investigation is to find out if a regime shift to high turbidity and strong tidal amplification is developing in the system. The results of the analysis show that both the hydraulic head and the tidal amplification have increased over time. The tide in this part of the estuary is flood-dominant, but the flood-dominancy is decreasing in time. These developments of the tide can be plausibly explained by a decrease of the river width followed by gradual deepening in the river. The most upper part of the Scheldt Estuary still behaves normally as a not too muddy system. No decisive answer can be given whether or not a regime shift towards a high-turbid system with strong tidal amplification may develop. How the system will develop depends on the change in capacity of pumping mud towards the upper reaches of the estuary. The increasing tidal amplitude can enhance this capacity although the flood-dominance itself is decreasing. Further study is recommended to better specify the potential danger of a regime shift to high-turbid system.
\end{abstract}

Keywords Tidal amplification $\cdot$ Scheldt Estuary $\cdot$ Tidal asymmetry $\cdot$ Hydraulic drag

\section{Introduction}

Water levels, probably the easiest data to measure in an estuary, contain important information about the estuary. Tidal wave changes its amplitude while propagating from the sea into an estuary, resulting in amplification or attenuation (= negative amplification, therefore only amplification used hereafter) of the tide. The tidal wave in an estuary can also deform causing changes in tidal asymmetry because the propagation velocity varies with variations in a water level. Amplification and deformation of the tidal wave in an estuary are directly related to the physical characteristics (morphology, hydraulic drag, etc.) of an estuary (Dronkers 1964; Amin 1983; Friedrichs and Aubrey, 1988; Dilorenzo et al. 1993;

Responsible Editor: Emil Vassilev Stanev

Zheng Bing Wang

zheng.wang@ deltares.nl

1 Deltares, Delft, The Netherlands

2 Faculty of Civil Engineering and Geosciences, Delft University of Technology, Delft, The Netherlands

3 Waterbouwkundig Laboratorium, Antwerpen, Belgium
Wang et al., 2002; Jensen et al. 2003; Woodworth et al. 1991; Flick et al. 2003; Jay 2009; Jay et al. 2011; Winterwerp et al. 2013; Wang et al. 2014; Hoitink and Jay, 2016). The development of tidal amplification and deformation, determined by analysing the water level data at different stations, thus gives insight in the morphological development of the estuary.

In this study, we analyse the amplification and deformation of the tide in the Upper Scheldt Estuary. The direct motivation of this analysis is the concern about a possible shift of the Scheldt Estuary from a low turbid and weak amplification regime towards a high turbid and strong amplification regime. Such a regime shift would be caused by the non-linear interaction between sediment dynamics and tidal motion and can be triggered by human interference such as deepening or narrowing of the estuary (Winterwerp and Wang 2013; Winterwerp et al. 2013), see Fig. 1.

The objective of the analysis is to explore if such a regime shift is developing in the Scheldt Estuary. The questions to be answered are as follows:

I. What is the present state of the Upper Scheldt Estuary concerning turbidity and tidal amplification? 


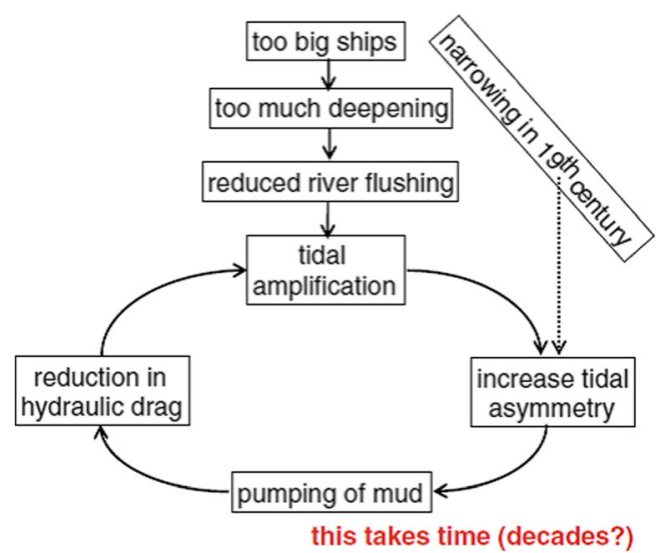

Fig. 1 Conceptual positive feedback loop inducing regime shift (After Winterwerp and Wang 2013)

II. Is there a danger that the Scheldt Estuary will become hyper-turbid with strong tidal amplification?

The regime shift to high turbidity and strong tidal amplification is characterised by a.o. a decrease in the hydraulic drag as a result of sediment-induced stratification (Munk and Anderson 1948; Vanoni 1946; Taylor and Dyer 1977; Villaret and Trowbridge 1991; Winterwerp et al. 2009). To find out if the hydraulic drag in the estuary is decreasing, we will examine the development of the tidal amplification, tidal asymmetry and the water surface slope under the influence of the river discharge. The following research questions will be addressed by analysing the available water level data:

1. How is the tidal amplification changed?

2. How is the mean water surface slope along the estuary changed?

3. How is the deformation of the tide changed?

4. If so, what are the causes of these changes?

5. Is the hydraulic drag decreasing?

6. How will the turbidity, hydraulic drag and tidal amplification develop in future?

Likely the entire process towards such a regime shift takes time, probably decades. However, the actual regime shift may be sudden, in response to an event (Wang et al. 2014), or also may develop slowly over a time of months to years (Dijkstra et al. 2019).

\section{Study area, data and methods}

The Scheldt Estuary is located in Belgium and The Netherlands, and measures almost $200 \mathrm{~km}$, from its mouth at the North Sea to the weirs/sluices in Ghent. We do not consider the upper reaches in Belgium and France beyond Ghent. In The Netherlands, the estuary is known as the
Western Scheldt. In Belgium, the river is known as the Lower and Upper Sea Scheldt (Fig. 2). The salinity intrusion limit migrates in the Lower Sea Scheldt with the tide and river flow, while the Upper Sea Scheldt is fresh (Winterwerp et al. 2013). The Port of Antwerp is located along the Lower Sea Scheldt, about $90 \mathrm{~km}$ from the mouth. The freshwater flow at Schelle varies between 30 and $300 \mathrm{~m}^{3} / \mathrm{s}$, with a long-term mean of about $120 \mathrm{~m}^{3} / \mathrm{s}$. The averaged discharge at Melle, which is more relevant for the present study, is about $35 \mathrm{~m}^{3} / \mathrm{s}$. The tide in the estuary is semi-diurnal. The averaged tidal range at the mouth of Western Scheldt (Vlissingen) is about $3.7 \mathrm{~m}$, increasing landwards to about $5.4 \mathrm{~m}$ at Tielrode ( $\sim 100 \mathrm{~km}$ from the mouth) and then decreases further upstream to about $2.6 \mathrm{~m}$ at Melle ( $150 \mathrm{~km}$ from mouth), see Fig.3.

A possible regime shift, as concerned by Winterwerp et al. (2013), would be expected in the Sea Scheldt, i.e. the Belgium part of the estuary. This is the narrow part of the estuary (Fig.2) where the largest changes occurred in the tidal range (Fig. 3). A complicating feature of the Sea Scheldt is its branching structure. To avoid this complication, the present study focuses on the most upper part of the estuary, i.e. the section between the tidal stations Dendermonde and Melle (Fig. 2). This part contains no tributaries and is not influenced by salinity intrusion.

For this study, the HW and LW records at the stations Dendemonde and Melle from 1971 to 2015 are collected, the full tidal signal is not available. Each record contains the water level (LW or HW) and time. The daily river discharge at Melle in the same period is collected as well.

The method for analysing the HW-LW records at each station is depicted in Fig. 4. A time frame indicated by the box is considered, analysing 5 data records. The first 4 records are used to determine (averaged) LW and HW. The last record is needed for determining the (averaged) rising and falling periods. Each time step, the box is moved by one data point, resulted in the same number of records in the output file as in the input file. The averaged HW (/LW) is equal to the average of the first two HW (/LW) values. The tidal range is equal to the difference between the averaged HW and the averaged LW. The mid-tide is determined as the average of the averaged HW and the averaged LW. The daily difference is determined by taking the averaged value of the difference between the two HW values and that between the two LW values. The rising (/falling) period is determined by taking the averaged value of the two rising (/falling) periods.

This way of analysis is similar but not identical to the method used by Wang et al. (2014), who determined the (lunar) daily values of the diurnal, semi-diurnal and quarterdiurnal tidal components by Fourier series analysis. No Fourier series analysis can be carried out because of the lack of water level records with a small time interval. However, the results of the two analyses contain similar information for the 
Fig. 2 The study area: the most upstream part of the Scheldt Estuary, between Melle and Dendermonde

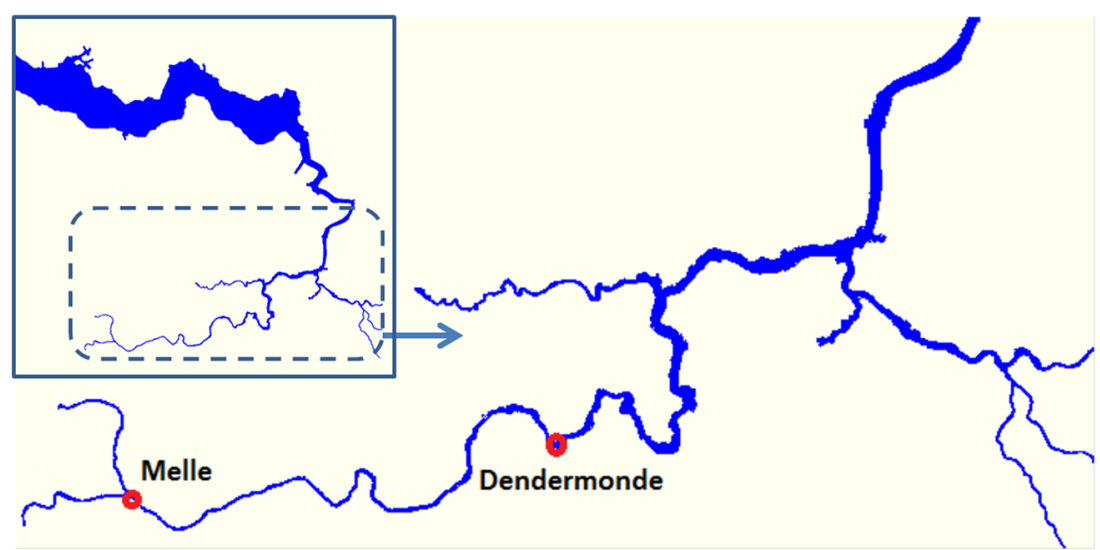

same characteristics of the tidal wave in the estuary. In Table 1, an overview of the characteristics of the tide and the corresponding parameters in the output of the two analyses is given.

These methods are better suited for identifying short-term changes than standard harmonic analyses (see e.g. Pawlowicz et al. 2002), as they provide day-to-day variations. Short-term changes can be caused by e.g. variations of the upstream river discharge. A drawback of these methods is that the results show scatters due to short-term variations. However, these can be filtered out by time averaging using a proper averaging period. Most of the scatters are caused by the spring-neap variation (Wang et al. 2014). Therefore, the results are presented after smoothing by a moving-average over 57 data points (a spring-neap cycle). Similar approaches such as wavelet analysis have also been used in earlier studies (Jay and Flinchem 1997a, Jay and Flinchem 1999).
The amplification factor is determined as the ratio between the tidal ranges at the two stations, Melle/Dendermonde. This parameter indicates how the tidal range changes between the two stations in the estuary. Any change in time of this parameter is an indication for changes in the physical conditions in the estuary. This way of analysis has some similarity with the admittance method (Munk and Cartwright 1966). Instead of using the astronomical potential in the admittance method, the measured tide at the downstream station is used as reference.

The hydraulic head is determined as the difference between the mid-tides at Melle and at Dendermonde. The direct cause of the hydraulic head is the river discharge. The way in which this parameter depends on the river discharge provides another indication of the physical condition of the river section, especially the hydraulic drag.

The ratio between the rising and falling periods is an indicator of the tidal asymmetry. This indicator is in particular

Fig. 3 Evolution of tidal range in the Scheldt Estuary, corrected for 18.6-year cycle (after Winterwerp et al. 2013, see also Kuijper and Lescinski 2012)

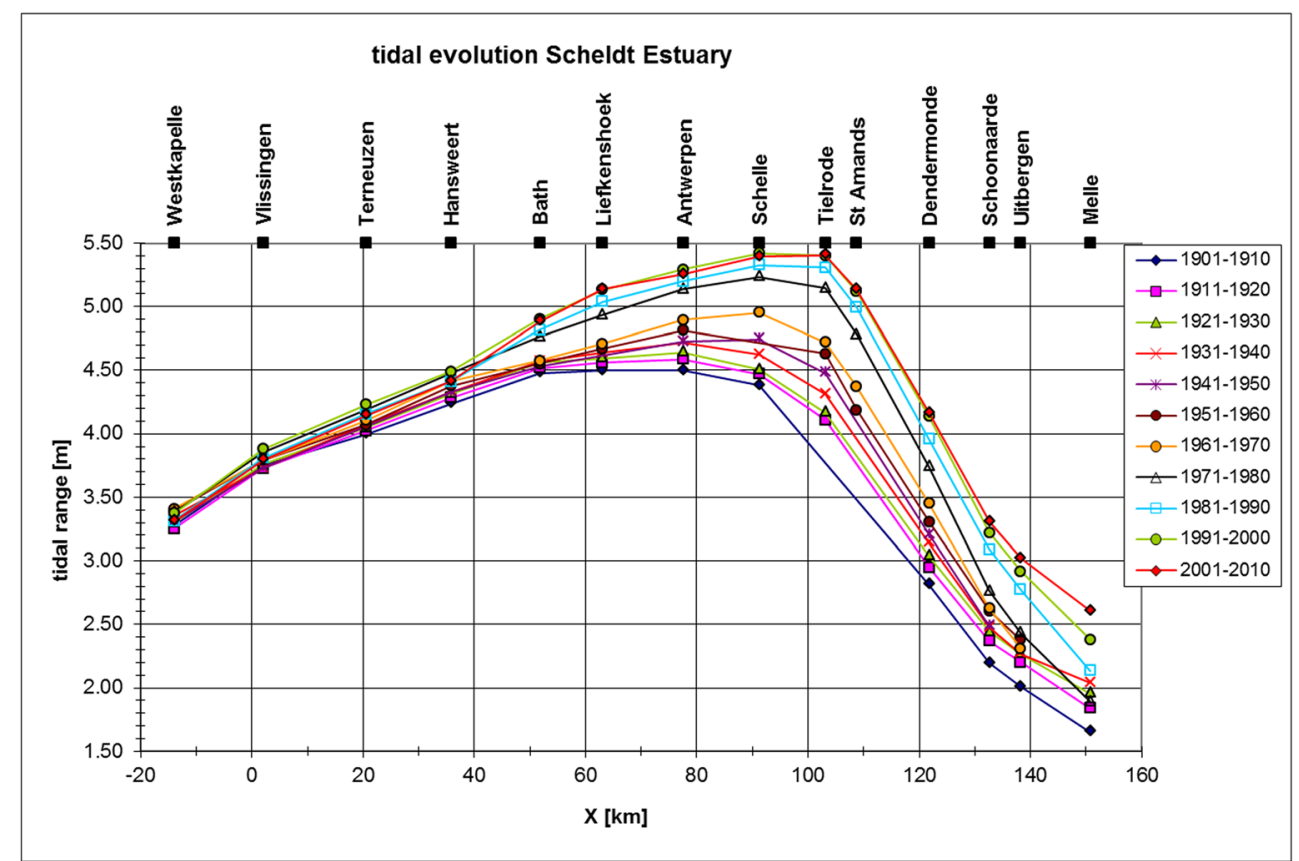




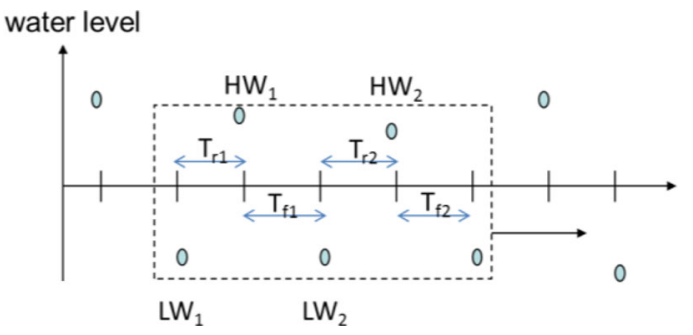

Fig. 4 Analysis of the HW-LW dataset

meaningful under conditions of low river flow, as in the Sea Scheldt. The tide at a station is flood-dominant if this ratio is smaller than one, and ebb-dominant if it is larger than one, provided river flows are not too large. The physical condition between the two stations influences the difference in this ratio indicating tidal asymmetry over the river stretch between these two stations.

The river discharge from upstream influences not only the hydraulic head but also the amplification and deformation of the tidal wave between the two stations (Vandenbruwaene et al. 2016). Therefore, the data of river discharge at Melle are also collected for the analysis.

\section{Results}

The tidal range at the downstream station Dendermonde considerably increased since 1971 (Fig. 5). Most increase occurred during the second half of the 1970s, and another period of increase is from the end of 1980s to the end of 1990's. In addition to a long-term trend, clear fluctuations can be observed in the development, even after filtering out the spring-neap variation. The fluctuation has a period of 1 year, thus representing seasonal variations.

The same seasonal variation can also be observed in the amplification factor, defined as the ratio between the tidal ranges at the upstream station Melle and the downstream station Dendermonde (Fig. 5). It is related to the variation of the river discharge (Fig. 6). High river discharge corresponds to a lower tidal range and weaker amplification (Figs.6 and 5). The amplification factor has also a longterm increasing trend. Most increase occurred between the beginning of the 1980s and mid 1990s and in the beginning of this century.
$H W=\left(H W_{1}+H W_{2}\right) / 2 \quad L W=\left(L W_{1}+L W_{2}\right) / 2$

Tidal range $=H W-L W \quad$ Mid-Tide $=(H W+L W) / 2$

$T_{r}=\left(T_{r 1}+T_{r 2}\right) / 2 \quad T_{f}=\left(T_{f 1}+T_{f 2}\right) / 2$

Indicator tidal asymmetry $=T_{r} / T_{f}$

The river discharge varies also from year to year in addition to the seasonal variation (Fig.6), but there is no consistent long-term trend.

The tidally averaged water surface slope along the river section between the two tidal stations is represented by the hydraulic head, defined as the difference between the midtides at Melle and at Dendermonde. Understandably, the hydraulic head is even more correlated to the river discharge. Higher river discharge causes larger hydraulic head (Fig. 7). Due to this correlation, the development of the hydraulic head in time is dominated by the seasonal and inter-annual fluctuations. Nevertheless, an increase of the water head since 1971 can still be observed. The increase mostly occurred in the 1970s. This becomes clearer by comparing the relations between the hydraulic head and the river discharge in different periods (Fig. 9). As a tide also has influence on the hydraulic head, the comparison is made for different tidal range classes. For the same river discharge and the same tidal range class, the hydraulic head in the period 1980s is larger than in the 1970s, but there is much less difference between the 1980s and the most recent period (since 2011), see Fig. 7 and especially Fig. 9. As an example, the hydraulic head for tidal range between 3.5 and $4 \mathrm{~m}$ (the three right panels in Fig. 9) and river discharge around $250 \mathrm{~m}^{3} / \mathrm{s}$ is about $1.2 \mathrm{~m}$ in $1971-1981$, about $1.4 \mathrm{~m}$ in 1981-1990 and about $1.6 \mathrm{~m}$ in 2011-2015.

In Fig. 8, the relation between the amplification factor and the tidal range (at Dendermonde) is depicted for the two periods and two river discharge classes. In most estuaries, the amplification factor decreases with the increasing tidal range because a larger tidal range corresponds to a stronger tidal flow inducing more frictional dissipation of the tidal wave (Jay 1991; Godin 1999; Wang et al. 2014). Only in high turbid estuaries this effect can be compensated by the decrease of hydraulic drag due to higher suspended
Table 1 Corresponding parameters from the two analyses for the various characteristics of tide

\begin{tabular}{lll}
\hline Characteristic of tide & Fourier series & HW-LW analysis \\
\hline Mean water level & Average water level $\mathrm{a}_{0}$ & Mid-tide $=(\mathrm{HW}+\mathrm{LW}) / 2$ \\
Tidal amplitude & Amplitude semi-diurnal comp. $\mathrm{a}_{2}$ & Tidal range \\
Tidal asymmetry & Quarter- and semi-diurnal comp. $\mathrm{a}_{4} / \mathrm{a}_{2}, \ldots$ & Difference falling and rising per. \\
\hline
\end{tabular}


Fig. 5 Development of the tidal range at Dendermonde (blue) and the amplification factor (red). The spring-neap variation is filtered out by a moving average over 57 data points

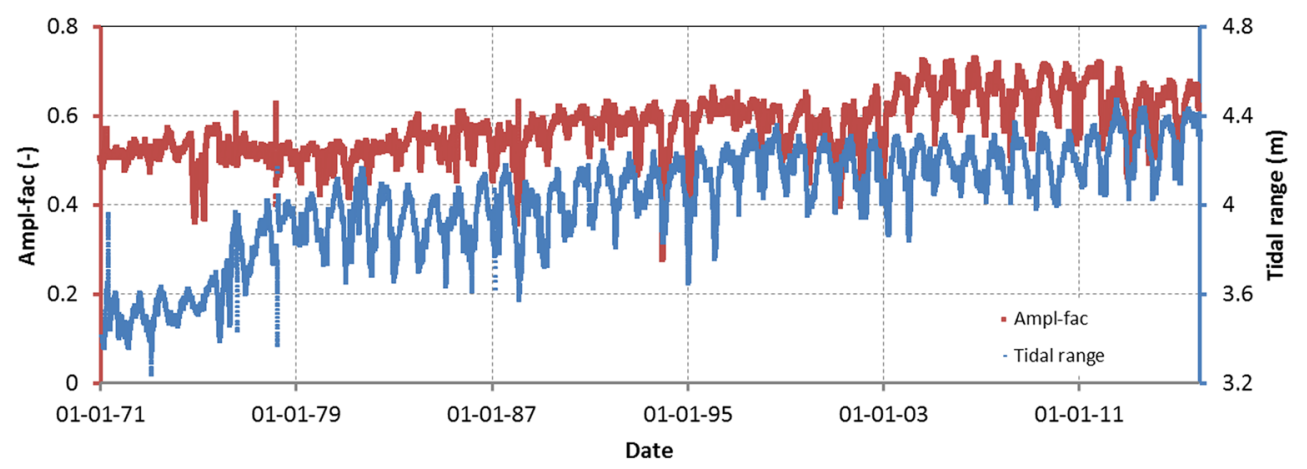

sediment concentration when a tidal range is large and tidal flow is strong. Apparently, the Upper Sea Scheldt shows this normal behaviour and there is no clear change in this behaviour in time. The tidal range and the amplification factor increased in time as indicated by the shift of the data cluster for the more recent period to right and up with respect to the earlier period.

The tidal asymmetry is represented by the ratio between the rising period $T_{r}$ and falling period $T_{f}$. A smaller value of this ratio means that the tide is more flood-dominant. In Fig. 10, the development of this ratio $T_{r} / T_{f}$ at Melle is depicted together with the river discharge $Q$. Higher river discharge corresponds with lower $T_{r} / T_{f}$, explaining the seasonal and inter-annual fluctuation of this ratio. A clear longterm increasing trend of the ratio can be observed in Fig. 10, implying that the tide at Melle has been becoming less flood-dominant.

The deformation of the tide within the river section between the two stations can better be indicated by the difference in the $T_{r} / T_{f}$ ratio at the two stations. This is depicted in Fig. 11 by showing the ratio and the difference between the stations Melle and Dendermonde. The ratio between the two stations is most of the time smaller than 1 implying that the vertical tide at Melle is more flood-dominant than at Dendermonde. The long-term trend is that the ratio between Melle and Dendermonde increases in time, implying that the deformation of the tide in this river section becomes smaller in time. In the most recent period, the ratio between the two stations is close to 1 , meaning that the tidal wave is hardly deformed during the propagation between the two stations.

\section{Discussions}

Concerning the developments in time, the findings from the analysis of the water level and river discharge data can be summarised as follows:

- There is no systematic trend in the river discharge variation in addition to the seasonal and inter-annual fluctuations.

- The tidal range at the downstream station Dendermonde increased in time, rapidly in mid 1970s, then gradually, in addition to the spring-neap variation and seasonal and inter-annual fluctuations corresponding to the river discharge variation.

- Amplification factor increased gradually, in addition to clear seasonal variations and spring-neap variations.

- Hydraulic head increased in mid 1970s, in addition to seasonal variation and spring-neap variation.

- The deformation of the tide in the river section between the two stations causes the flood-dominance to increase in the upstream direction. This deformation becomes less in time making the tide to become in the considered river section less flood-dominant in time.

From the observations, the following relations between the various factors can be derived:
Fig. 6 Development of the amplification factor (smoothed) and the river discharge (not smoothed)

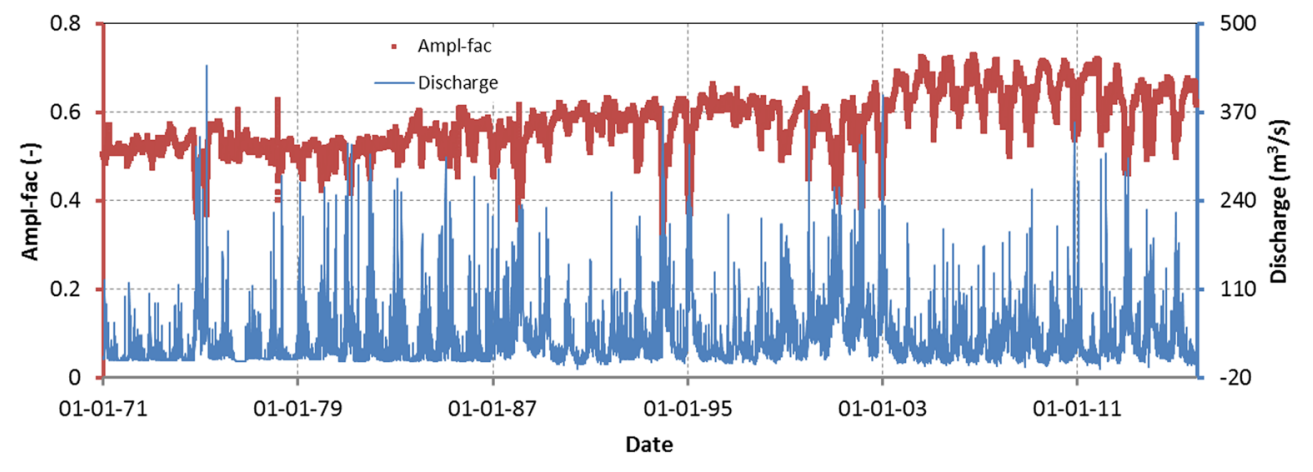


Fig. 7 Development of the hydraulic head and the river discharge

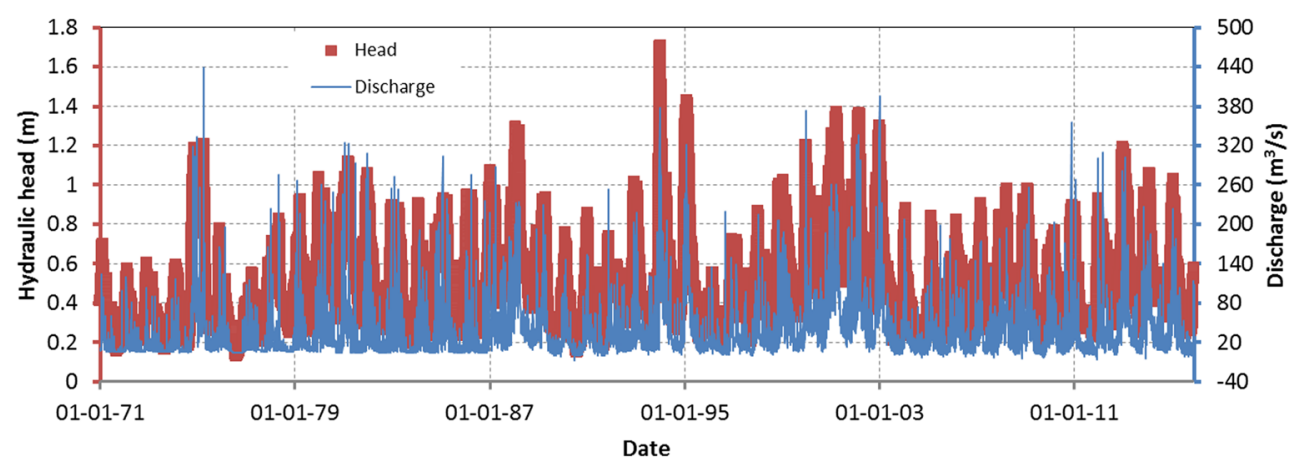

- The tidal range at both stations depends on the river discharge. A higher river discharge corresponds to a smaller tidal range in the whole river section under consideration.

- The amplification factor and the hydraulic head are both closely related to the river discharge. A higher river discharge causes a larger hydraulic head and smaller amplification factor.

- The amplification factor and hydraulic head are also closely related to the tidal range at the downstream end. A larger tidal range causes larger hydraulic head and smaller amplification factor.

- The ratio between rising and falling periods is closely related to the river discharge. The ratio is smaller if the river discharge is larger.

Theoretically the tidal wave propagation in the river section are determined by three factors, viz. (1) the upstream boundary condition represented by the river discharge at Melle, (2) the downstream boundary condition represented by the tide at Dendermonde, and (3) the physical condition of the river section. This means that the development of the hydraulic head, the tidal amplification and the tidal asymmetry should all be explained by the changes of these three factors. With the known development of the upstream and downstream boundary conditions, we can try to derive from the observed developments how the physical conditions of the river section have been changing.

\section{$5<Q<10$}

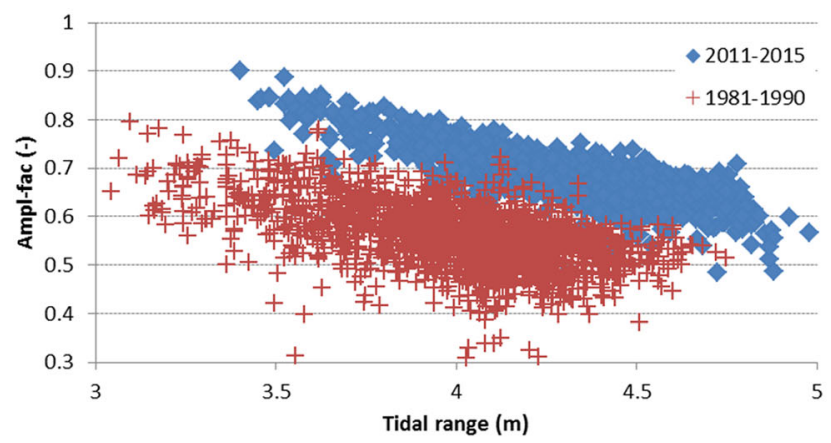

Fig. 8 Relation between tidal range (at Dendermonde) and amplification
From the tidal propagation point of view, the relevant physical conditions of a river section include its morphology and the effective roughness. The morphology of the river determines the tidal storage which is mainly determined by the total width of the river in the intertidal zone, and the flow carrying capacity which is mainly determined by the depth (e.g. Friedrichs and Aubrey, 1988). These different aspects of the physical conditions of the river influence the tidal flow in different way. By investigating the various characteristics of the tidal propagation, we attempt to find out if the effective roughness of the river is changing. Decrease of the effective roughness would be an indication of an ongoing regime shift.

A complicating issue is that tides and river discharge interact through quadratic bed friction, which reduces the tidal wave intrusion as discharge increases (Godin 1991, 1999; Kukulka and Jay 2003a; Kukulka and Jay 2003b; Beardsley et al. 1995; Gabioux et al. 2005; Moftakhari et al. 2013). This explains the seasonal and inter-annual fluctuations of the tidal range at the downstream station Dendermonde and the amplification factor corresponding to the river discharge variation. Another opposite effect of river discharge is via the change in water depth. A larger river discharge causes a higher (mean) water level increasing the water depth and thus reducing the hydraulic drag (Guo et al. 2015). The first effect is apparently more dominating. These complicating issues have been overcome by making distinctions of different river discharge classes (Fig. 8).

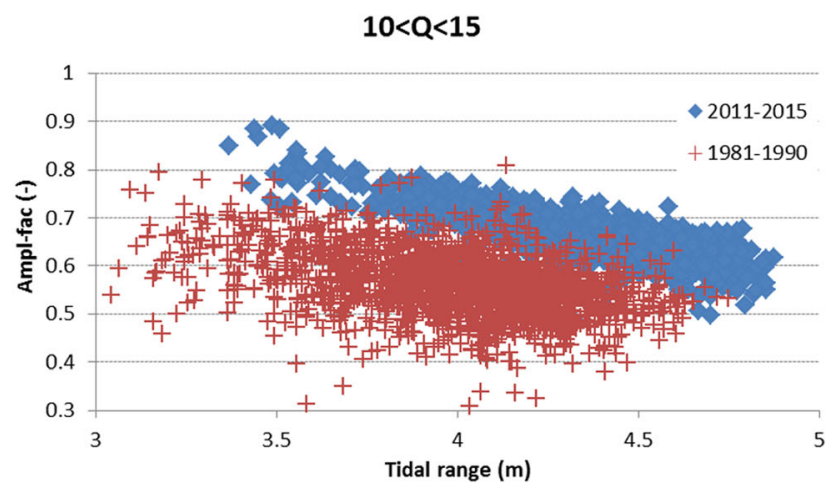


$1971-19803<\mathrm{TR}<3.5$

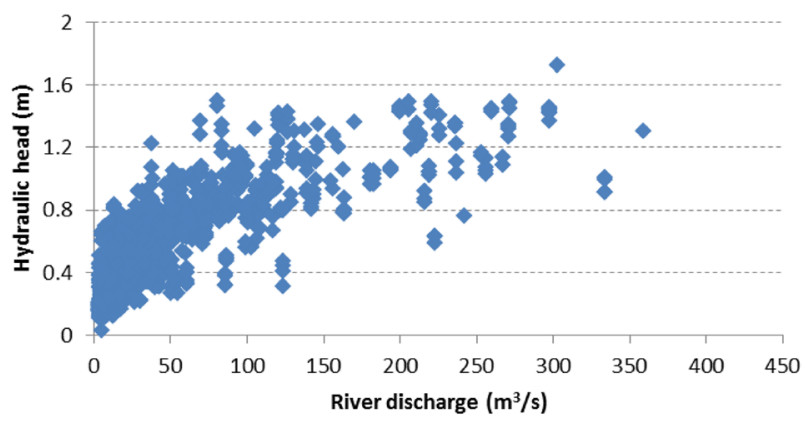

$1981-19903<T R<3.5$

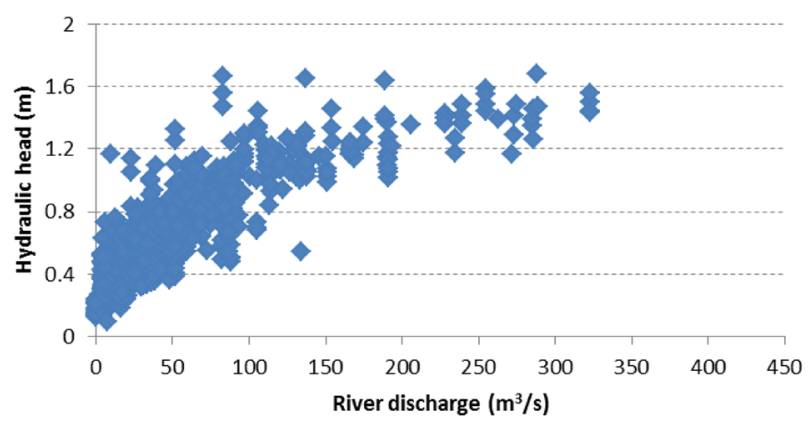

2011-2015 TR<3.5

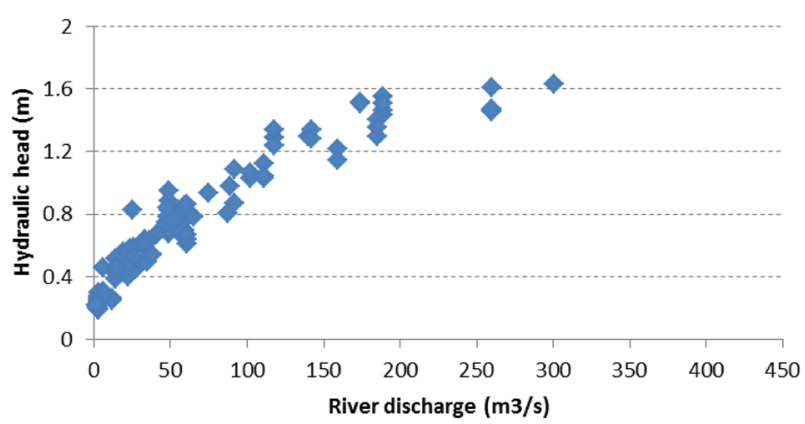

$1971-19803.5<T R<4$

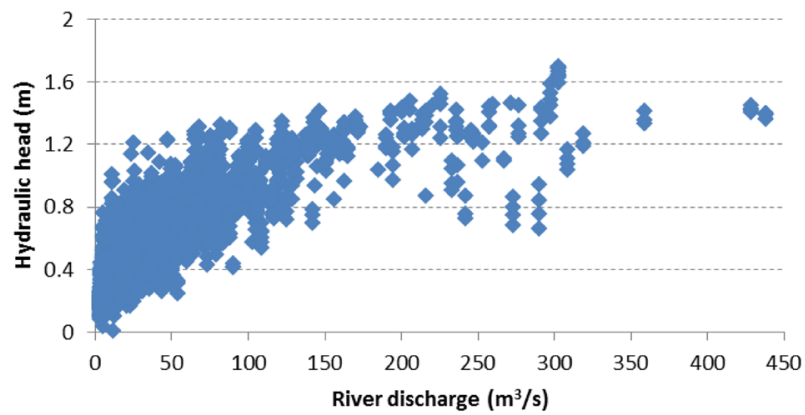

$1981-19903.5<T R<4$

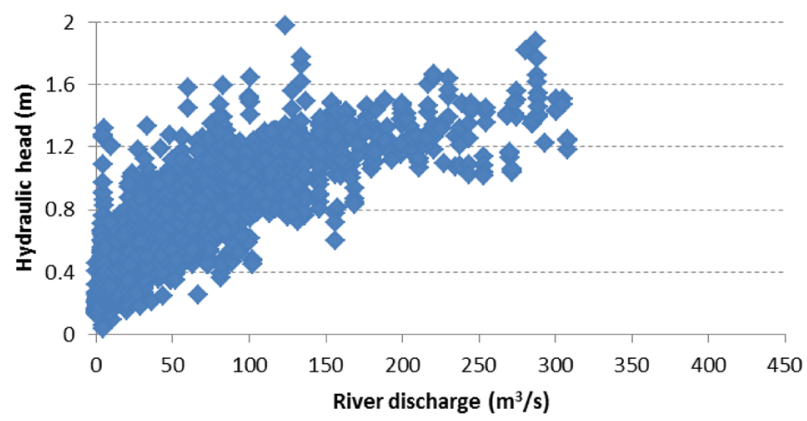

2011-2015 $3.5<T R<4$

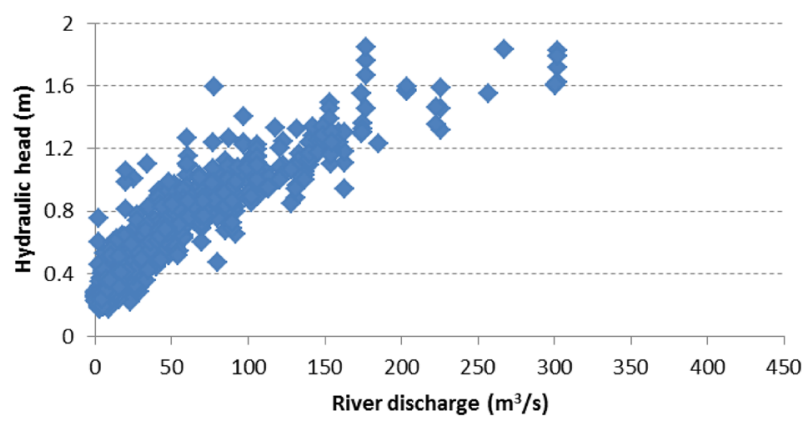

Fig. 9 Relation between hydraulic head and river discharge, $\mathrm{TR}=$ tidal range in $\mathrm{m}$

The downstream boundary condition is thus not independent of the upstream boundary conditions. This is because we are looking at the most upper part of the estuary, so the downstream station Dendermonde is under influence of the river discharge. This does not cause problems in our analysis because we focus on the changes of the tide from the downstream station to upstream station by looking at, e.g. the amplification factor.

Another complicating issue is that also the tide at the downstream boundary has influence on the hydraulic drag. A larger tidal range causes a higher tidal flow velocity increasing the resistance to the river flow (Jay 1991; Godin 1999; Hoitink et al. 2017). Therefore it is necessary to distinguish the various tidal range classes in the investigation to the change of the hydraulic head (Fig. 9). The data analysis results show that a larger tidal range causes larger hydraulic head (Fig. 9) and a smaller amplification factor (Fig. 8). This indicates the normal behaviour of a not too muddy estuary.

Both hydraulic head and amplification factor have increased in time (Figs.6, 7 and 9). This is interesting and requires explanation. First, this cannot be explained by the changed boundary conditions. No trend in the river discharge has been found. Moreover, a change in the upstream river discharge would have the opposite effect on the two parameters. An increase of the river discharge would cause an increase of the hydraulic head but a decrease of the amplification factor. The increased tidal range at the downstream station causes an increase of the hydraulic head but a decrease of the amplification. Second, it cannot be simply explained by a change in hydraulic drag via a change of the water depth or roughness. A decrease of the hydraulic drag is needed to explain the increased amplification factor, but an increase of the 
Fig. 10 Development of the ratio between the rising period and falling period at Melle (red) and the river discharge (blue)

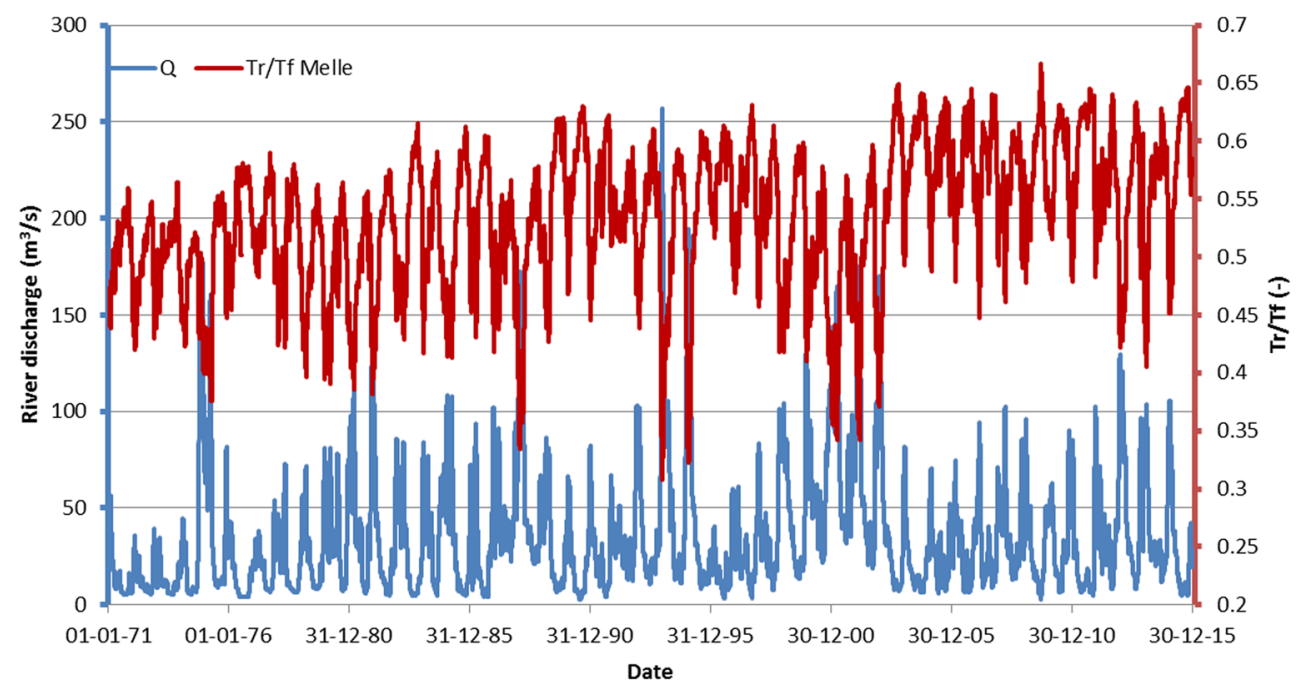

hydraulic drag would be needed for the increased hydraulic head. A logical explanation for the development of the hydraulic head and the amplification factor is a change in the tidal storage. A decrease of the storage width of the river can explain increase of both the hydraulic head and the amplification factor (see, e.g. Winterwerp and Wang 2013). However, the time developments of the two do not show the same behaviour. The increase of the hydraulic head is mainly concentrated in the mid-1970s (Figs. 7 and 9), whereas the increase of the amplification factor occurred much more gradually (Fig. 6). The most plausible explanation is therefore a decrease of the storage width in the mid 1970s followed by a gradual decrease of the hydraulic drag. Vandenbruwaene et al. (2013) indeed report that a decrease in width at MHWL if the present situation is compared with that in the 1960s (see also Van Braeckel et al., 2006). The decrease of the storage width did not cause a clearly sudden change of the amplification factor because it also increases the residual flow velocity due to the river discharge. The gradual decrease of the hydraulic drag has less effect on the hydraulic head because of the compensating effect of the increased tidal range.

The remaining question is what has caused the gradual decrease of the hydraulic drag, due to an increase of the water depth and/or a decrease of the effective roughness? The analysis of the development of the tidal asymmetry showed that the deformation of the tidal wave in the river section causing the tide upstream more flood-dominant than downstream has become weaker in time. This can better be explained by an increase of the water depth rather than a decrease of the roughness. An increase in water depth is indeed reported by Vandenbruwaene et al. (2016). Thus, the decreased hydraulic drag is probably caused by deepening of the river, but a change of the effective roughness cannot be excluded. The gradual deepening is likely to be caused by a morphodynamic response of the river to deepening further downstream (around Antwerp) for navigation and sand mining in addition to the narrowing of the river section itself.
Fig. 11 Development of the ratio (blue) and the difference (red) between the rising period/falling period ratios at Melle and Dendermonde

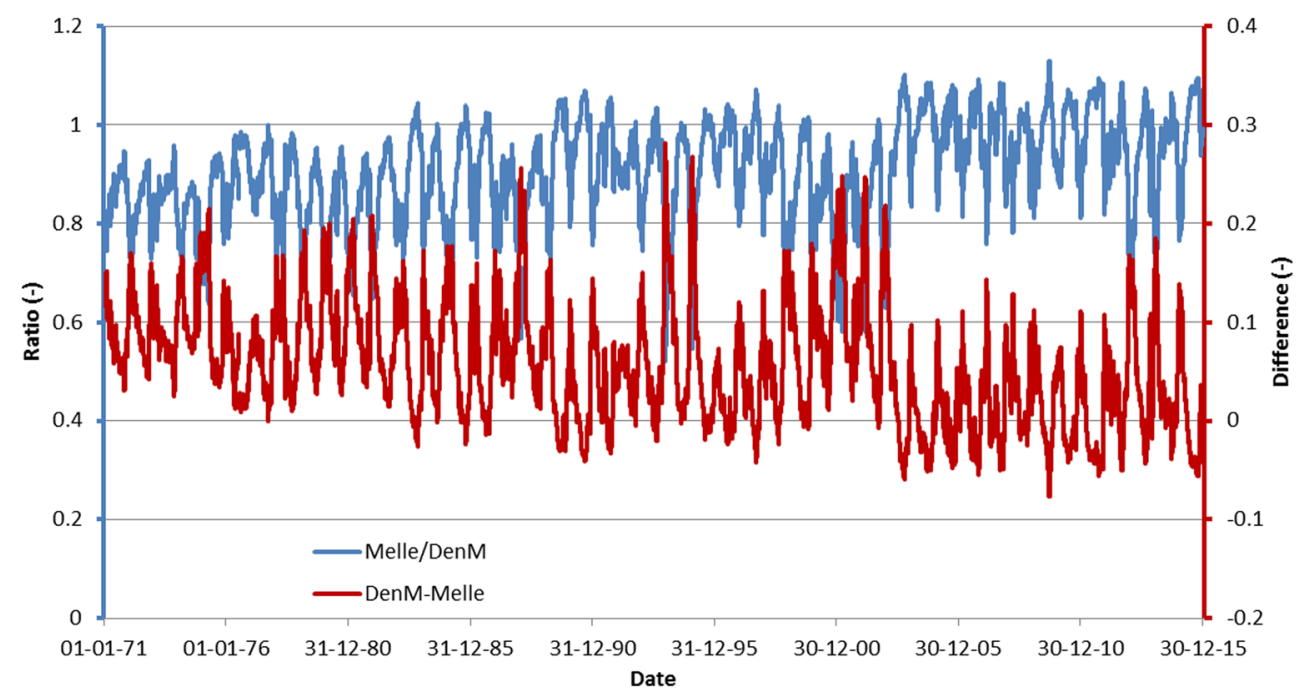


The present analysis does thus not give a decisive answer to the research question 5. It is not clear if the positive feedback as shown in Fig. 1 is developing in this part of the estuary. The turbidity in the estuary has been monitored by taking water samples at the water surface along the estuary. By analysing this data set until 2013, Vandenbruwaene et al. (2015) concluded that the sediment concentration is strongly influenced by the variations of flow within a tide, tidal range and the river discharge, but could not detect a long-term trend of the sediment concentration. A more detailed analysis on the same data set until 2016 was carried out by IMDC (2017). In addition to phase within a tide, tidal range and river discharge, disposal of dredged sediment has been identified as an influencing factor for the sediment concentration in the estuary. Concerning the trend in time of the residue (thus in addition to the effects of changing tidal range and changing sediment disposal), an insignificant increasing trend for the yearly mean sediment concentration in the study area of the present analysis is found. It is also found that the trend is different between the summer (dry season) and the winter (wet season): a significant increasing trend in the summer and an insignificant decreasing trend in the winter. Further monitoring and study on the development of sediment concentration are required.

Without a decisive answer to the research question 5, it becomes also more difficult to answer the research question 6. A key element here is the development of the capacity of 'pumping mud' (indicated on Fig.1) to this part of the estuary. The present analysis gives two contradicting indications for this development. First, the flood-dominance of the tide in the river is decreasing, implying that the trapping of mud in this most upper part of the estuary can be decreasing. Second, the tidal amplitude is increasing, implying that the tidal flow is becoming stronger so the capacity of pumping mud to this part of the estuary can increase even if the flooddominance of the tide is decreasing. Using an idealised model, which is verified to be able to reproduce the regime shift as defined by Winterwerp et al. (2013) in the Ems Estuary due to deepening (Dijkstra et al. 2019); Dijkstra (2019) concluded that deepening alone cannot increase the sediment concentration in the Scheldt Estuary. The model results show that deepening causes a decrease of the sediment concentration averaged over the whole estuary, and an increase in the most upstream part of the estuary as considered in the present analysis due to a shift of the turbidity maximum zone. The model results also show that disposal of dredged sediment increases the sediment concentration. Based on these findings, it is still not fully clear if deepening of the estuary for navigation, accompanied by changing dredging and dumping activities, will increase the turbidity in the estuary. Further analysis is needed to find out which development is stronger.

\section{Conclusions}

In summary, the following conclusions are drawn:

- The tidal amplification in the most upper part of the Scheldt Estuary has become stronger in time while the upstream river discharge does not show any long-term trend and the tidal range at the downstream boundary has been increasing.

- The hydraulic head, represented by the difference between the mid-tides at the upstream and downstream stations, has increased, mainly in the 1970 s.

- The deformation of the tidal wave in the most upper part of the Scheldt Estuary causing flood-dominance has become less in time.

- The developments of the hydraulic head, the tidal amplification and the deformation of the tide can be explained by a decrease of the (storage) width in the 1970s followed by a gradual deepening of the river.

- Contradicting indications have been found for the capacity in pumping mud to the upper part of the Scheldt Estuary: decreasing flood-dominance but increasing tidal amplitude.

Based on these findings, we now go back to the two questions we want to answer (section 1):

I. What is the present state of the Upper Scheldt Estuary concerning turbidity and tidal amplification?

The most upper part of the Scheldt Estuary still shows the normal behaviour of a not too muddy estuary. The tidal amplitude and the tidal amplification are both increasing. The turbidity still needs to be analysed.

II. Is there a danger that the Scheldt Estuary becomes hyperturbid with strong tidal amplification?

No decisive answer can be given concerning the development of the hydraulic drag in the most upper part of the Scheldt Estuary. The key for the future development is the change in the capacity of pumping mud into this part of the estuary. This capacity is probably increasing due to the increase of the tidal amplitude although the flooddominance of the tide is decreasing. Further study is required to identify the potential danger of a regime shift to hyper-turbidity.

As the data do not suggest a feedback between SPM and tidal properties, deepening of the Scheldt up to now did not lead to the positive feedback loop of Fig. 1, causing hyperturbid conditions. This may be attributed to the geometrical 
and hydrodynamic properties of the Scheldt (Dijkstra 2019), and/or to a shortage of sediments, and/or sufficient accommodation space to immobilize large amounts of SPM.

Open Access This article is distributed under the terms of the Creative Commons Attribution 4.0 International License (http:// creativecommons.org/licenses/by/4.0/), which permits unrestricted use, distribution, and reproduction in any medium, provided you give appropriate credit to the original author(s) and the source, provide a link to the Creative Commons license, and indicate if changes were made.

\section{References}

Amin M (1983) On perturbations of harmonic constants in the Thames Estuary. Geophys J R Astron Soc 73:587-603

Beardsley RC, Candela J, Limeburner R, Geyer WR, Lentz SJ, Castro BM, Cacchione D, Carneiro N (1995) The M2 tide on the Amazon shelf. J Geophys Res 100(C2):2283-2319

Dijkstra YM (2019) Regime shift in sediment concentrations in tidedominated estuaries. PhD thesis, Delft University of Technology, ISBN: 978-94-6380-311-3. Available from repository.tudelft.nl

Dijkstra YM, Schuttelaars HM, Schramkowski GP, Brouwer RL (2019) Modeling the transition to high sediment concentrations as a response to channel deepening in the Ems River Estuary. J of Geophys Res: Oceans 124:1578-1594. https://doi.org/10.1029/ 2018JC014367

DiLorenzo JL, Huang PM, Thatcher L, Najarian TO (1993) Dredging impacts of Delaware estuary tides. Proc 3rd Int Conf sponsored by the waterway, port, coastal and ocean division, ASCE estuarine and coastal modeling III, oak brook, IL, 86-104

Dronkers JJ (1964) Tidal computations in river and coastal waters. Elsevier, New York

Flick RE, Murray JF, Ewing LC (2003) Trends in United States tidal datum statistics and tide range. J Waterw Port Coast Ocean Eng 129:155-164

Friedrichs CT, Aubrey DG (1988) Non-linear tidal distortion in shallow well-mixed estuaries: a synthesis. Estuarine, Coastal and Shelf Science 27(5):521-545

Gabioux M, Vinzon SB, Paiva AM (2005) Tidal propagation over fluid mud layers on the Amazon shelf. Cont Shelf Res 25(2005):113-125

Godin G (1991) Frictional effects in river tides, in Progress in Tidal Hydrodynamics. Edited by BB Parker, John Wiley New York, pp. 379-402

Godin G (1999) The propagation of tides up rivers with special considerations on the upper Saint Lawrence River. Estuar Coast Shelf Sci 48:307-324

Guo L, Van der Wegen M, Jay DA, Matte P, Wang ZB, Roelvink D, He Q (2015) River-tide dynamics: exploration of nonstationary and nonlinear tidal behavior in the Yangtze River estuary. J Geophys Res Oceans 120:3499-3521. https://doi.org/10.1002/2014JC010491

Hoitink AJF, Jay DA (2016) Tidal river dynamics: implications for deltas. Rev Geophys 54:240-272. https://doi.org/10.1002/2015RG000507

Hoitink AJF, Wang ZB, Vermeulen B, Huismans Y, Kästner K (2017) Tidal controls on river delta morphology. Nat Geosci 10:637-645. https://doi.org/10.1038/NGEO3000

IMDC (2017) Multivariate analysis of sediment concentration from water samples in the Upper Scheldt Estuary (in Dutch). Report I/NO/ 11498/17.207/GLE/

Jay DA (1991) Green's law revisited: tidal long-wave propagation in channels with strong topography. J Geophys res VOL. 96, NO. Cll, PAGES 20,585-20,598
Jay DA (2009) Evolution of tidal amplitudes in the eastern Pacific Ocean. Geophys Res Lett 36:L04603

Jay DA, Flinchem EP (1997) Interaction of fluctuating river flow with a barotropic tide: a demonstration of wavelet tidal analysis methods. J Geophys Res 102(C3):5705-5720

Jay DA, Flinchem EP (1999) A comparison of methods for analysis of tidal records containing multi-scale non-tidal background energy. Cont Shelf Res 19:1695-1732

Jay DA, Leffler K, Degens S (2011) Long-term evolution of Columbia River tides. J Waterw Port Coast Ocean Eng 137:182-191

Jensen J, Mudersbach CH, Blasi CH (2003) Hydrological changes in tidal estuaries due to natural and anthropogenic effects. Proc 6 Int MEDCOAST 2003-Conf, Ravenna, Italy

Kuijper C, Lescinski J (2012) LTV Veiligheid en Toegankelijkheid. Sub project B: Data Analysis Western Scheldt. Report 1204405. Deltares

Kukulka T, Jay DA (2003a) Impacts of Columbia River discharge on salmonid habitat: I. A non-stationary fluvial tide model. J Geophys Res 108:3293

Kukulka T, Jay DA (2003b) Impacts of Columbia River discharge on salmonid habitat: II. Changes in shallow-water habitat. J Geophys Res 108:3294

Moftakhari HR, Jay DA, Talke SA, Kukulka T, Bromirski PD (2013) A novel approach to flow estimation in tidal rivers. Water Resour Res 49:4817-4832. https://doi.org/10.1002/wrcr.20363

Munk WH, Anderson ER (1948) Notes on a theory of the thermocline. J Mar Res 7:276-295

Munk WH, Cartwright DE (1966) Tidal spectroscopy and predication. Philos Trans R Soc Lond Ser A 259:533-581

Pawlowicz R, Beardsley B, Lentz S (2002) Classical tidal harmonic analysis including error estimates in MATLAB using T TIDE. Comput Geosci 28(2002):929-937

Taylor PA, Dyer KR (1977) Theoretical models of flow near the bed and their implications for sediment transport. The Sea 6:579-601

Van Braeckel A, Piesschaert F, van den Bergh E (2006) Historische analyse van de Zeeschelde en haar getijgebon den zijrivieren. 19e eeuw tot heden. INBO report INBO.R.2006.29

Vandenbruwaene W, Plancke Y, Verwaest T, Mostaert F (2013) The longterm hydro-geomorphological evolution of the Schelde estuary: a comparison between 1951-1960 and 2000-2010. Versie 2.0. WL Rapporten, 00_158. Flanders Hydraulics Research: Antwerp. III, 23 pp

Vandenbruwaene W, Wildemeersch K, Plancke Y, Vanlede J (2015) On the short- and long-term SPM variations in the Scheldt Estuary. Eproceedings of the $36^{\text {th }}$ IAHR World Congress, 28 June-3 July 2015, The Hague, The Netherlands

Vandenbruwaene W, Meire D, Vanlede J, Plancke Y, Vanlier de E, Verwaest T, Mostaert F (2016) Integraal plan Boven-Zeeschelde: deelrapport 2. Getijrapport Boven-Zeeschelde, Rupel en Durme. versie 6.0. WL Rapporten, 13_131. Waterbouwkundig Laboratorium: Antwerpen. IX, $62+62$ p. bijlagen pp

Vanoni VA (1946) Transportation of suspended sediment by water. ASCE Transactions 111(2267):67-133

Villaret C, Trowbridge JH (1991) Effects of stratification by suspended sediments on turbulent shear flows. J Geophys Res 96(C6):10659 10680

Wang ZB, Jeuken MCJL, Gerritsen H, de Vriend HJ, Kornman BA (2002) Morphology and asymmetry of the vertical tide in the Westerschelde estuary. Continental Shelf Research 22(17):25992609

Wang ZB, Winterwerp JC, He Q (2014) Interaction between suspended sediment and tidal amplification in the Guadalquivir Estuary. Ocean Dyn 64:1487-1498. https://doi.org/10.1007/s10236-014-0758x1487-1498 
Winterwerp JC, Wang ZB (2013) Man-induced regime shifts in small estuaries-I: theory. Ocean Dyn 63:1279-1292. https://doi.org/10. 1007/s10236-013-0662-9

Winterwerp JC, Lely M, He Q (2009) Sediment-induced buoyancy destruction and drag reduction in estuaries. Ocean Dyn 59(5):781-791

Winterwerp JC, Wang ZB, Van Brackel A, Van Holland G, Kösters F (2013) Man-induced regime shifts in small estuaries-II: a comparison of rivers. Ocean Dyn 63:1293-1306. https://doi.org/ 10.1007/s10236-013-0663-8

Woodworth PL, Shaw SM, Blackman DL (1991) Secular trends in mean tidal range around the British Isles and along the adjacent European coastline. Geophys J Int 104:593-609 